\title{
Debonding of carbon-fibre-reinforced polymer plate from concrete beams
}

\section{R. N. Swamy and P. Mukhopadhyaya}

\section{B. P. Hughes, Solihull, UK}

The authors are to be congratulated on a very useful paper and timely warning on the possibility of plate debonding in a sudden brittle manner in beams reinforced with carbon-fibrereinforced polymer (CFRP) plate. It is shown that if the flexural strength of reinforced concrete (RC) beams is increased without a similar increase in shear strength, sudden brittle failure of the beam becomes a distinct possibility. Furthermore, while end anchorages are generally essential, they are not necessarily a sufficient requirement to ensure that debonding does not occur anywhere along the beam.

The authors also observe the similarities, and contrast the differences, between CFRP plate and steel plate bonding of RC beams. Both methods increase the overall stiffness of the beam, reduce crack width, delay the appearance of the first crack and extend the ultimate load-bearing capacity. They are also both equally effective for strengthening pre-cracked and uncracked beams. A third method, which could be included with these similarities, is the bonding of reinforced polymer-modified mortar (PMM) sheets to RC beams.

Ongoing research at Birmingham University has been concerned with the development of high-strength PMMs with tensile strengths at least comparable with the adhesive resins used for bonding steel and CFRP plates. In an early application for strengthening RC beams, PMM with seven-day MOR strengths of up to $20 \mathrm{MPa}$ was used. ${ }^{31,32}$ Sheets of PMM were compacted by rolling, cut into strips and then rolled onto the soffits and sides of the beams in a similar manner to the CFRP laminate. However, since the fresh PMM strips had little strength and were heavier than the present CFRP laminate, the method was less convenient for repairing RC beams from below. PMM, however, is ideally suited for application from above, and where excellent durability and resistance to abrasion and other forms of attack are important, such as overlays for concrete pavements. The ongoing research has continued and very high performance PMMs with MOR strengths of up to $40 \mathrm{MPa}$ have now been developed. This is more than sufficient to ensure good bond with the concrete and facilitate innovative continuous bonded overlays for the repair of concrete pavements comparable with the methods now readily available for RC beams. All three methods-steel plate, CFRP plate and reinforced PMM overlayscan benefit by highlighting the similarities and by contrasting the differences between them.

\section{Authors' reply}

The authors want to thank Professor Hughes for his thoughtful comments on their paper, and for drawing attention to the technique of bonding PMM sheets to strengthen RC beams. We want to assure Professor Hughes that we, and the first author in particular, are fully aware of his valuable work on the use of PMM sheets for structural strengthening. The use of polymer/ latex-modified concrete, with or without reinforcement is, however, not new, as is shown in Reference 33 where tests are reported to repair and strengthen lightweight and normal weight RC beams, $140 \times 200 \times 2420 \mathrm{~mm}$ in size. In these tests both high-strength conventional and latex-modified mortars were used, and the reinforcing elements in the repair mortar consisted of lightweight high tensile strength polymer geogrids and/or epoxy-coated bars. The geogrids are manufactured from high-density polyethylene, and apart from their total resistance to water and chemical corrosion, these geogrids impart very high ductility, impact resistance and energy absorption properties to concrete. ${ }^{34,35}$ The repaired beams showed higher serviceability loads, excellent deflection and crack control and very good ductility. The repaired beams also maintained composite action and full structural integrity without any bond distress throughout the loading range right up to failure. ${ }^{33}$ One of the methods used to achieve full composite action was to use a specially developed bonding agent consisting of a slurry of cement latex which provided an extremely tight bond between the old and new concretes.

Professor Hughes is absolutely correct in identifying the practical difficulties of bonding PMM sheets for repairing RC beams from below. The first author has overcome this difficulty by injecting a highly flowable conventional/latex mortar but, in spite of this, one has to recognise that the method is cumbersome compared to epoxy bonding of steel or FRP plates.

There are also other similar techniques of structural strengthening, such as the use of ferrocement laminates, ${ }^{36}$ but we have to recognise that the development of the use of both the PMM sheets and ferrocement laminates is very much in its early stages, and we need to know a lot more of their structural implications before they can be used in practice. In contrast to PMM sheets and ferrocement laminates, the use of steel plates and CFRP sheets has been researched worldwide. Steel plates have been used extensively in practical applications, and CFRP sheets are beginning to find an equally wide application all 
over the world. However, the emphasis and focus of our paper, as noted by Professor Hughes and described in other papers from our research group, is that plate bonding technology is not a simple mechanical process, and that engineers need to have a clear and full understanding of the structural implications of such strengthening systems. The use of bonded reinforced PMM sheets and ferrocement laminates appears to have the potential to strengthen RC beams, and is structurally feasible, but whether they can compete with steel and FRP materials on a cost-effective basis remains to be seen.

On the other hand, the advantages and benefits of using PMMs and polymer-modified concretes, with or without reinforcement, for concrete pavements and/or for their repair cannot be questioned. ${ }^{37-39}$ The use of latex-modified concrete for corrosion protection of bridge decks is widespread in many states in North America and; indeed, many state Departments of Transportation consider it to be mandatory where de-icing salts are used extensively. However, for such applications there is no need to manufacture PMM or polymer-modified concrete in the form of sheets. Unfortunately, polymer-modified concrete appears to be least understood and used in the UK and Europe in general.

\section{Li, Naugyang Technological University, Singapore} In their paper on debonding of CFRP plate from concrete beams, the authors presented details of their test results and discussion. End anchorages, additional intermediate anchorages along the span and lateral confinement of the compression zone by steel plates were provided to overcome bond slip and plate separation at the ends and the slip of the plate itself along the span at critical sections of cracking. It appears that the intermediate anchorage and end anchorage play a very important part, but the role of lateral confinement of the compression zone by the steel plates is not clear.

The CFRP strengthened beams failed in flexure, shear and plate debonding as described in Table 4 (test results) and shown in Figs 4-9. In particular, for beams A2, B4 and B5, plate debonding and pulling off occurred at peak load. However, the authors predicted the failure load only on the basis of flexural theory. Based on the constitutive relation for materials as given in BS 8110, ACI code and Eurocode 2, the predictions were sensible and consistent. Failure loads should be predicted according to their failure modes. Beams A2, B4 and B5 failed when the plates debonded and pulled off as indicated in Figs 5 and 9. In such cases, the prediction of failure loads should be based on the mechanism of plate debonding rather than flexural failure criteria.

The structural ductility of the specimens was also discussed in the paper. Ductility of conventional RC beams is a measure of the energy absorption capacity. Ductility of RC members is defined as a ratio of deflection or curvature or rotation values at ultimate yield. These definitions depend mainly on the distinct yielding level and post-yielding plateau of steel reinforcing bars. To evaluate the ductility of CFRP strengthened beams is complicated due to the linear stress-strain relationship of CFRP plates until failure. There is no distinct point in the load-deflection curve from which the stiffness of the member reduces sharply. Fig. 7 confirmed this. The authors proposed two definitions of ductility indices, taking account of the post- peak load behaviour of the beams. One of the deflection ductility indices, $\mu_{\mathrm{D} 2}$, and one of the energy ductility indices, $\mu_{\mathrm{E} 2}$, were defined as follows.

\begin{tabular}{|l|l|}
\hline & $\mu_{\mathrm{D} 2}=\frac{\text { (midspan deflection at 75\% of post-peak load) }}{\text { (midspan deflection at tension steel yield) }}$ \\
\hline & $\begin{array}{l}\mu_{\mathrm{D} 2}= \\
\text { (area of load-deflection curve up to 75\% of post-peak load) }\end{array}$ \\
\hline
\end{tabular}

All ductility indices were calculated for all the beams tested and the results were shown in Table 6 . The question is that beams A2, B4 and B5 did not exhibit any post-peak behaviour as shown in Figs 5 and 9. However, it is not known how the authors calculated the ductility indices which use the post-peak behaviour of the members.

\section{Authors' reply}

The authors thank Mr Li for his contribution to the discussion of the above paper. Mr Li has raised three important questions pertaining to the performance characteristics of beams strengthened with bonded CFRP laminates. The authors' response is given below.

Many tests now show that the location, configuration and combination of the externally bonded anchorage systems are critical to the achievement of the best performance of the strengthened composite beam. ${ }^{40}$ In particular, lateral confinement of the compression zone increases its resistance to crushing, and enhances the contribution to strength and ductility of the compression concrete. Tests reported in Reference 7 show that plates bonded to the compression concrete, encompassing the entire maximum bending moment region and beyond, can act as confining reinforcement and enhance the flexural capacity of the FRP plate bonded beam. Further, more recent tests ${ }^{41}$ have shown that lateral confinement of the compression concrete under the load points and, where appropriate, in the compression zone as well, can form an effective technique to enhance the shear capacity of the strengthened composite beam. Thus, lateral confinement of the compression zone has many important roles to play in the overall structural behaviour of the strengthened beam where both flexural and/or shear strengthening are involved.

$\mathrm{Mr}$ Li has suggested that the prediction of the failure loads of beams A2, B4 and B5 should be based on the mechanism of plate debonding rather than flexural failure criteria. This is not quite correct. If one examines the data in Table 4 , it will be seen that the internal tensile reinforcement had undergone extensive yielding in all the beams and that the concrete strain at the extreme compression face was also well beyond the value normally associated with flexural failures. So all the beams, including beams A2, B4 and B5, showed all the signs of flexural failure, and the application of flexural failure criteria based on strain compatibility to predict their failure loads is appropriate, valid and rational. Indeed, the results in Table 5 confirm this, and emphasise that the theoretical load predictions are very satisfactory. However, what the tests show is that in the case of plate-bonded strengthened beams, even 
where flexural failure conditions are supposed to have been reached, there are important secondary features associated with the failure modes of the beams, such as plate debonding and pulling off and critical shear cracking, following the achievement of the peak loads. These secondary failure features cannot be ignored because although they are unlikely to enhance the failure loads much further, they have significant implications on ductility and safety, as shown in the paper. Further, these phenomena make it difficult to separate the primary and secondary causes of failure. This is one of the very important lessons to be learned from plate bonding technology. The tests reported here show that these secondary failure features should be avoided at all costs, and emphasise again the role of the different types of externally bonded anchorage systems necessary in the design of such beams if they are to give high performance.

Mr Li has referred to the mechanism of plate debonding. This becomes particularly critical in those beams where plate debonding is the primary mechanism of failure, and occurs well before the yielding of the internal tension reinforcement and the compression concrete reaching its crushing strain. In the authors' view, a clear understanding of the mechanisms of CFRP debonding from the RC beam under these conditions is far from adequate to develop a rational and reliable analytical failure load prediction model at this stage. A critical evaluation of existing theories predicting the premature plate debonding phenomenon shows that the calculated peak stresses triggering the plate debonding cannot form a reliable basis to explain or design the prevention of premature plate debonding failures. ${ }^{42,43}$

Finally, Mr Li asks how the authors calculated the ductility indices, which are based on post-peak behaviour, of beams A2, B4 and B5 which did not exhibit any post-peak behaviour. The explanation is simple. In cases where there was little or no visible or measurable post-peak behaviour, the authors assumed that the load dropped to zero instantly from the last recorded point on the load-deflection plots such as Figs 5 and 9 without any further deflection. Hence, the deflection at 75\% post-peak load would be the same or very close to the deflection at peak load. Similar arguments also apply to the area under the loaddeflection curve. In fact, a careful study of the ductility indices in Table 6 will reveal that these assumptions are truly reflected in those values. The ductility indices $\mu_{\mathrm{D} 1}$ and $\mu_{\mathrm{E} 1}$ are based on peak loads, whereas $\mu_{\mathrm{D} 2}$ and $\mu_{\mathrm{E} 2}$ are based on the $75 \%$ postpeak load. As can be seen in Table 6, the values of the ductility index $\mu_{\mathrm{D} 1}$ are very close or exactly the same as $\mu_{\mathrm{D} 2}$ for the beams A2, B4 and B5. The same observation is true for ductility indices $\mu_{\mathrm{E} 1}$ and $\mu_{\mathrm{E} 2}$. For a wider discussion of ductility and ductility indices, the authors would refer Mr Li to References 8, 19, 22, 40 and 44 .

\section{REFERENCES}

31. Hughes B. P. and Evbuomwan N. F. O. Polymer modified ferrocement enhances strength of reinforced concrete beams. Construction and Building Materials Journal, 1993, 7, No. 1, Mar., 9-12.
32. Hughes B. P. and LuBis B. Roller compacted sheets of polymer modified mortar. Cement and Concrete Composites, 1996, 18, No. 1, Feb.

33. Swamy R. N. and Ali A. M. A. H. Structural response of reinforced concrete beams repaired with new materials. Proceedings of the 2nd International Conference on Deterioration and Repair of Reinforced Concrete in the Arabian Gulf, Bahrain, 1987, 1, 171-183.

34. SWAmy R. N., Jones R. and OldRoyd P. The behaviour of tensar reinforced cement composites under static loading. Proccedings of a Symposium on Polymer Grids Reinforcement in Civil Engineering, London, March 1984, 222-232.

35. Swamy R. N. and Jones R. Polymer grid reinforcement for corrosion control and concrete repair. Proceedings of an International Conference on Structural Faults and Repair, London, May 1985, 49-56.

36. Paramasivam P., Ong K. C. G. and Lim C. T. E. Ferrocement laminates for strengthening RC T-beams. Cement and Concrete Composites, 1994, 16, No. 2, 143-152.

37. SWAmy R. N. Durability of concrete composites with polymers. Proceedings of the 8th International Congress on Polymers in Concrete, Oostende (Van Gemert D. (ed.)), July 1995, 21-26.

38. RAmli M. and Swamy R. N. Development of polymermodified cement systems for durable concrete construction. Proceedings of the 3rd Asia-Pacific Conference on Structural Engineering and Construction, 1996, 375-382.

39. Swamy R. N. and Ramli M. A rational mix design methodology for latex modified concrete. Proceedings of the 3rd South African Conference on Polymers in Concrete, Johannesburg, July 1997.

40. Spadea G., Bencardino F. and Swamy R. N. Optimizing the performance characteristics of beams strengthened with bonded CFRP laminates. Materials and Structures, 2000, 33, 119-126.

41. SWamy R. N., Mukhopadhyaya P. and Lynsdale C. J. Strengthening for shear of RC beams by external plate bonding. The Structural Engineer, 1999, 77, No. 12, 19-30.

42. Mukhopadhyaya P. and Swamy R. N. Critical review of plate anchorage stresses in premature debonding failures of plate bonded reinforced concrete beams. Proceedings of the 4th International Symposium on Fibre Reinforced Polymer Reinforcement for Reinforced Concrete Structures, Baltimore, 1999. ACI Publication SP-188, 1999, 359-368.

43. MukHopadHyaya P. and SwAmy R. N. Interface shear stress a new design criteria for plate debonding. Journal of Composites for Construction (in press).

44. Spadea G., Swamy R. N. and Bencardino F. Ductility or deformability? Reinforced concrete beams strengthened with externally bonded carbon fibre reinforced polymer laminates. Proceedings of the 4th International Symposium on Fibre Reinforced Polymer Reinforcement for Reinforced Concrete Structures, Baltimore, 1999, Selected Presentation Proceedings, 171-180. 